92.5 for motor, 30 for disability) and 10 CAYP at 1 year (median 98.25 for motor, median 28 for disability). Gross Motor Function Measure (GMFM) score was available for 9 CAYP at baseline (median 40), 8 CAYP at 1 year (median 47) and 7 CAYP beyond 1 year (median 43.1). Changes in GMFM and BFMDRS did not reach statistical significance.

Pain was measured with paediatric pain profile, classified into most troublesome pain (MT) and pain on a good day (GD), available for 14 CAYP at baseline and 6 CAYP at 1 year. There was marked improvement in median MT pain (29 at baseline to 17 at 1 year) but less significant improvement in median GD pain (16 at baseline to 13.5 at 1 year).

Conclusions For a heterogenous cohort of CAYP with motor disorders, ITB appeared to improve ease of care and comfort as indicated by change in CPCHILD score. Multiple measures are required to fully capture benefits seen in this cohort, which should be focused on their individual needs for intervention.

\section{G77(P) RESPIRATORY TRACT INFECTION IN CHILDREN WITH A NEURODISABILITY - MICROBIOLOGY, ANTIBIOTIC CONSUMPTION AND HOSPITAL ADMISSION - A SERVICE EVALUATION FOR A HIGH-RISK GROUP}

${ }^{1,2} \mathrm{~L}_{\text {Marrable, }}{ }^{1,2} \mathrm{JRF}$ Sanner, ${ }^{2} \mathrm{M}$ Flanigan, ${ }^{2} \mathrm{~T}$ Wolff, ${ }^{1,2} \mathrm{MN}$ Hurley. ${ }^{1}$ School of Medicine: Division of Child Health, Obstetrics and Gynaecology, University of Nottingham, Nottingham, UK; ${ }^{2}$ Nottingham Children's Hospital, Nottingham University Hospitals NHS Trust, Nottingham, UK

\subsection{6/archdischild-2020-rcpch.58}

Aims Children with neurodisability (ND) have an increased risk of respiratory tract infections (RTI). We aimed to establish the organisms implicated in pulmonary infection in children with ND in our area in the context of antibiotic provision, as well as document hospital admissions within this population.

Methods The City Rapid Access Physiotherapy Service (RAPS) cares for children with ND who have frequent RTIs. A random number generator was used to select a sample of 30 children from a complete list of 74 children accessing this service. Respiratory tract samples are taken when RTI is suspected. Patient records were used to investigate respiratory microbiology, hospital admissions and inpatient antibiotic provision, from $30 / 09 / 15$ to $30 / 09 / 19$ inclusive.

Results Of the 30 children, 15 were male; 14 had cerebral palsy, 6 had a neurodegenerative disease, 5 had a neuromuscular condition and 5 had other complex ND conditions. A total of 184 admissions were documented across 26 patients; the average admission length was 9.5 days (range 0-116 days). The average number of positive respiratory microbiology samples per patient was 8 (range 0-54). 7 patients had no positive respiratory samples. $185(76.8 \%)$ positive isolates were viral and $56(23.3 \%)$ were bacterial. Common isolates are presented in table 1.

18 patients received prophylactic antibiotics, notably azithromycin (16). In total, 176 courses of inpatient antibiotics were prescribed; 36 were co-amoxiclav. The average number of inpatient antibiotics prescribed per child was 6 (range 041). Lower RTI was the most common (46.1\%) documented reason for antibiotic prescription.

Conclusion Viruses are most commonly isolated from children with ND during an exacerbation of symptoms, although many bacteria are also implicated. Infections in these patients lead to frequent inpatient admissions and are managed by a wide
Abstract G77(P) Table 1 Organisms most commonly isolated in respiratory samples from a random sample of 30 children with ND

\begin{tabular}{lll}
\hline Organism & Number of patients isolated in & Number of isolations \\
\hline Rhino/enterovirus & 19 & 113 \\
Parainfluenza virus & 15 & 38 \\
Respiratory syncytial virus & 14 & 37 \\
Human coronavirus & 10 & 18 \\
Adenovirus & 8 & 14 \\
Metapneumovirus & 9 & 12 \\
Pseudomonas aeruginosa & 6 & 17 \\
Haemophilus influenzae & 7 & 15 \\
\hline
\end{tabular}

variety of antibiotics, of which co-amoxiclav is the most commonly prescribed. It is uncertain whether there is an association between the microbiology and severity of disease.

\section{G78(P) ABSTRACT WITHDRAWN \\ G79(P) CYTOMEGALOVIRUS AND HERPES SIMPLEX VIRUS 1 \& 2 MENINGITIS AMONG CHILDREN WITH SUSPECTED MENINGITIS AT A TERTIARY EMERGENCY UNIT IN NIGERIA}

${ }^{1} \mathrm{~A}$ Akindolire, ${ }^{2} \mathrm{~A}$ Adigun, ${ }^{1} \mathrm{O}$ Tongo, ${ }^{1} \mathrm{AO}$ Asinobi, ${ }^{3} \mathrm{~A}$ Odaibo, ${ }^{3} \mathrm{D}$ Olaleye. ${ }^{1}$ Department of Paediatrics, University of Ibadan/University College Hospital Ibadan, Nigeria; ${ }^{2}$ University College Hospital Ibadan, Nigeria; ${ }^{3}$ Department of Virology, University of Ibadan, Ibadan, Nigeria

\subsection{6/archdischild-2020-rcpch.59}

Aim To determine the incidence of cytomegalovirus and herpes simplex virus $1 \& 2$ among paediatric emergencies presenting with suspected meningitis at the children's emergency room.

Methods It was a prospective cross sectional study of all consecutive paediatric emergencies over a period of three months. Patients were included in the study if they had any neurological signs such as but not limited to lethargy, coma seizures with or without fever. Clinical details were entered into a structured proforma. Cerebrospinal fluid (CSF) samples were obtained at admission and sent to the Virology Laboratory in a cold box. Deoxyribonucleic acid (DNA) extraction was done using commercially available DNA extraction kit by Jena Bioscience (Jena Germany) according to the manufacturer's instruction. The DNA was then tested for HSV $1 \& 2$ and CMV using gene specific primers in a multiplex reaction. Positive samples were detected after agarose gel electrophoresis using a trans illuminator.

Results Forty patients were recruited, 29 (72.5\%) males and $11(27.5 \%)$ females, with a mean age of $27.1 \pm 18.3$ months. The most common presenting clinical features were seizures 37 (92.5\%), fever 35 (87.5\%), lethargy 29 (72.5\%), poor feeding $23(57.5 \%)$ and coma $11(27.5 \%)$. Twenty (50\%) the patients had CSF positive for HSV 1, 13 (32.5\%) of whom were also positive for CMV and 12 (30\%) for HSV 2. Eleven patients $(27.5 \%)$ were positive for all three viruses.

Conclusion The high incidence of viral meningitis among children with suspected meningitis is consistent with findings from high income countries. Mortality and morbidity from meningitis remain high in this setting however, viral aetiology 
of meningitis is rarely considered or treated. The use of antiviral agents in meningitis have been shown to reduce morbidity and mortality from viral meningitis. Antiviral agents should therefore be considered in the management of meningitis in this setting in order to improve outcomes of patients and promote judicious use of antibiotics. Further research to describe the viral aetiology of meningitis in this setting is required.

\section{Quality improvement and patient safety}

\section{Plenary}

\section{P03 THE KIDZMED PROJECT: TEACHING CHILDREN TO SWALLOW TABLET MEDICATION}

\begin{abstract}
${ }^{1,2}{ }^{2}$ Tse, ${ }^{3} \mathrm{~N}$ Vasey, ${ }^{2} \mathrm{D}$ Dua, ${ }^{3} \mathrm{~S}$ Oliver, ${ }^{1} \mathrm{~V}$ Emmet, ${ }^{4} \mathrm{~A}$ Pickering, ${ }^{4,5} \mathrm{E}$ Lim. ${ }^{1}$ Department of Paediatric Nephrology, Great North Children's Hospital, Newcastle upon Tyne, UK; ${ }^{2}$ Medical School, Newcastle University, Newcastle upon Tyne, UK; ${ }^{3}$ Department of Paediatric Pharmacy, Royal Victoria Infirmary, Newcastle upon Tyne, UK; ${ }^{4}$ Department of Paediatric Immunology and Infectious Diseases, Great North Children's Hospital, Newcastle upon Tyne, UK: ${ }^{5}$ Institute of Health and Society, Newcastle University, Newcastle upon Tyne, UK
\end{abstract}

10.1136/archdischild-2020-rcpch.60

Aim Tablets are safer, more convenient and cheaper than liquid medications. Children and young people (CYP) often remain on liquids due to habit, reluctance to change or staff and parents' lack of knowledge about switching to tablets. We describe a quality improvement project to train staff and embed a system of converting eligible children to tablet medication.

Method Working with families and teams, we created an interactive training package with training video and comic poster. We ran interactive hour-long training sessions for staff. Using positive reinforcement and play, the trainer sat facing the learner with sweets or dummy capsules filled with sweets of increasing sizes.

Starting with one small team over 12 weeks we embedded a process for children $\geq 5$ years attending complex renal clinics to be converted from liquid to tablet medication unless contraindicated (e.g. swallowing or cognitive impairment). We overcame practical barriers by placing easily accessible 'switching kits' in clinic filled with the necessary dummy pills, awards and certificates as well as standardising clinic processes.

Results In the initial test of change in one team, over three months, 90 CYP were seen in 13 multi-disciplinary renal clinics, 25 were suitable for conversion to tablet medication. 21 CYP (median age 8.4 years range 5.1 to 15.5 ) were successfully converted (only one patient required two sessions). 36 medicines were switched, generating $£ 46588$ per year recurrent savings.

Feedback was good. Staff liked the opportunity for positive interaction with children and families appreciated the ease of obtaining tablet medications versus liquids.

Conclusion In a short timeframe it is possible to embed a system to convert children to tablet medication, improve the families' experience of obtaining medication and realise considerable cost savings. It requires staff training and cultural change. Pill swallowing is an easy skill to teach and learn and we encourage all paediatric departments and clinics to set up tablet schools. Since then our project has spread within our hospital via nurses and play specialists, regionally and beyond to larger audiences.

\section{G80 USING QUALITY IMPROVEMENT TO IMPROVE IDENTIFICATION AND SUPPORT OF FAMILIES LIVING IN POVERTY IN PAEDIATRIC PRACTICE}

${ }^{1,2} \mathrm{H}$ Zhu, ${ }^{1,2} 1 \mathrm{Ng},{ }^{2} \mathrm{~S}$ Bidgood, ${ }^{2} \mathrm{P}$ Cotterill, ${ }^{2} \mathrm{~J}$ Morris, ${ }^{3} \mathrm{~A}$ Okereafor, ${ }^{4} \mathrm{E}$ Sunderland, ${ }^{5} \mathrm{G}$ Singh. ${ }^{1}$ Community Paediatrics, Evelina Children's Hospital, London, UK; ${ }^{2}$ General Paediatrics, Kingston Hospital, Kingston upon Thames, UK; ${ }^{3}$ General Paediatrics, North Middlesex Hospital, London, UK; ${ }^{4}$ Adolescent Medicine, St George's Hospital, London, UK; ${ }^{5}$ Community Paediatrics, Newham University Hospital, London, UK

10.1136/archdischild-2020-rcpch.61

Aims Poverty is the most important determinant of child health in the UK associated with adverse health, developmental, educational and long-term social outcomes. Despite growing levels of child poverty, paediatricians feel powerless when faced with it. Training gaps and underdeveloped pathways lead to missed opportunities to help impoverished families.

Our aim was for $>80 \%$ of doctors in the paediatric assessment unit to ask about child poverty as part of their routine clinical assessments and to signpost families to local resources where appropriate.

Methods Measures:

- Percentage of doctors who asked about child poverty for the last patient clerked.

- Percentage of nurses and doctors aware of local resources for families living in poverty.

- Resources given and family feedback.

This project was piloted in an area with $21 \%$ child poverty but is expanding to areas with greater deprivation. Stakeholder focus groups co-designed screening questions for (a) nurses: 'how did you get to hospital/how will you get home?' and for (b) doctors: 'have you been on holiday in the last year?' These questions were used in addition to identifying poverty risk factors from the family and social history, which included: single parents, unemployment, $>3$ young children, chronic health conditions and social worker involvement. When appropriate, the bespoke child poverty leaflet was discussed with parents offering local resources to help increase income, provide essentials and increase participation.

Results At baseline, no doctors screened for child poverty or advised on local resources. Plan-do-study-act cycles were conducted to test screening questions, increase colleagues' buy-in and resource leaflet prescribing. The percentage screening for child poverty increased from 0\% in March 2019 to an average of $84 \%$ in July-August 2019 . The resource awareness percentage increased from $0 \%$ to $100 \%$. Patient feedback was extremely positive: 'thank you for being so thoughtful, you really helped me.'

Conclusion Paediatricians can play a significant role in helping families living in poverty. This quality improvement project demonstrates one approach to asking about child poverty in routine clinical assessments and for offering local resources to help empower families. Further PDSA cycles are recommended to promote sustainability and advocate multidisciplinary progress of social paediatrics across children's services in the UK.

\section{G81 POSTNATAL MANAGEMENT OF HYPOGLYCAEMIA - KEEPING MOTHERS AND BABIES TOGETHER}

S Mohamed Cassim, D Varghese, W Ramsay. Neonatal Unit, NHS Lanarkshire, Wishaw, UK

10.1136/archdischild-2020-rcpch.62 